\title{
Current Trends and outcomes: Endovascular Management in Arteriosclerosis Obliterans (ASO) of Lower Limb Vessels
}

\author{
Shahid Alam, Shi Wang ${ }^{2}$, Chengwei Liu ${ }^{3 *}$, Ismail Jan ${ }^{4}$, Mujahid Alizada ${ }^{5}$ \\ ${ }^{1}$ Department of Vascular Surgery, The First affiliated Hospital of Jiamusi University. \\ ${ }^{3 *}$ Department of Vascular surgery. The First Affiliated Hospital of Jiamusi University, \\ Jiamusi city, Heilongjiang province, P. R China \\ The Project Sponsored by the Scientific Research Foundation for the Returned Overseas \\ Chinese Scholars, State Education Ministry \\ ${ }^{1}$ imoonsk@hotmail.com, ${ }^{3 *}$ liucwcw@163.com
}

\begin{abstract}
Arteriosclerosis obliterans (ASO) or peripheral artery disease (PAD) is among one of the most common medical concerns that is responsible for high patient morbidity. Because of sedentary lifestyle and smoking ASO of lower limb vessels are now a considered with critical significance. Along with the different treatment method, the interventional procedure concerning Percutaneous Transluminal angioplasty (PTA) is the most successful procedure regarding the management of ASO of the lower limb vessels. The basic objective of this study is to determine the effect of PTA and compare the outcome of PTA -balloon dilatation with PTA stenting for the lesions of the lower limb vessels and to provide a proper conclusive indication of a particular management regarding endovascular management of lower limb vessel stenosis and osculation. Our study summarized with the following conclusion:
\end{abstract}

PTA and primary stenting of the lower limb vessels for management of ASO can be performed safely in early and in advanced PAD. The results seem to be an improvement over those of balloon angioplasty alone when compared with published literatures. In the intermediate term, treatment of PAD by primary Implantation of a self-expanding stent yielded results that were superior to those with the currently recommended approach of balloon angioplasty. This reduces the chance of re-occlusion and thus reduces the morbidity and provides a better patient outcome. Judging the review of the literatures and the outcome, PTA appears to be the most feasible, safe, and effective procedure of these days for the treatment of ASO. In long-term results, most of the study data demonstrated a high success rate of PTA stenting in comparison to balloon angioplasty in the treatment of PAD cases. In the view of this it is justified to say that PTA can be the primary choice for the management of Critical limb ischemia.

Keywords: Arteriosclerosis obliterans, Arteriosclerosis of lower limb vessels, Percutaneous transluminal angioplasty, PTA and Stenting, PTA balloon dilatation, PTA of Femoral artery, PTA of Popleteal artery, Bellow knee Percutaneous transluminal angioplasty.

\section{Methodology}

We made this review by systematically searching relevant literatures using multiple keywords and standardized terminology on NCBI Pub MED, Google Scholar and the other scientific website and international journals for publications describing randomized controlled trials (RCTs), Case presentation, and Original article related to the topic of our study.

\section{AN OVERVIEW OF ARTERIOSClEROSIS ObLITERANS (ASO)}

Arteriosclerosis obliterans, or peripheral artery disease (PAD), is one of the most common concerned medical conditions that adversely affects blood vessels and blood circulation of the lower extremities and may result in nerves and tissue damage. Cause by hardening or narrowing of the arterial walls and therefore reduced circulation to the peripheral tissue. "Intermittent claudication (IC)" is the main concerning symptom of peripheral artery disease (PAD) encountered in $10 \%$ of the population over 70 years of age, though serious complications can emerge in all age group. Exertional muscular pain that subside with rest, is experienced by $2 \%$ of people above 65 years of age in the effected cases of ASO. Additionally, patients may also develop night pain, non-healing ulcers, however, asymptomatic PVD is also seen in $90 \%$ of patients. ${ }^{[1]}$ The classical risk factors for PVD are smoking, diabetes mellitus, hypertension, and hyperlipidemia. Recent trials have also included chronic renal insufficiency ${ }^{[2]}$ elevated levels of C-reactive protein, ${ }^{[3]}$ and hyperhomocysteinemia. ${ }^{[4]}$ Edinburgh 
Claudication Questionnaire appeared to be $91 \%$ specific and $99 \%$ sensitive in patients with intermittent claudication. ${ }^{[5]}$

PAD is thought out as to be a set of chronic or acute syndromes due to arterial occlusion, commonly affect the lower limb vessels. Ischemia of the lower limbs can be classified as functional state that occurs when the blood flow is normal at rest but insufficient with the increase demand during exercise. Critical ischemia is produced when the reduction in blood flow results in a perfusion deficit at resting stage. The pathophysiologic mechanism of arterial insufficiency is based on the presence of arterial stenosis. An imbalance between the demand and supply of blood to peripheral tissues more or less abruptly cause a situation of acute ischemia of thrombotic origin. High risk plaques found in the arteries of the lower limbs are very stenotic, fibrous ${ }^{[6]}$ and hypercoagulable. These lesions are composed of a large extracellular lipid nucleus and abundant foamy cells, covered by a fibrous layer which bears a risk to be ruptured. ${ }^{[7]}$ This mechanism results in thrombosis that obliterates the vascular luminal patency. PAD causes the Muscles in these areas work twice as hard, during motion or at rest. Once PVD is suspected, ankle brachial index (ABI) testing should be performed, ABI less than 0.9 is consistent with PVD. However, this test will not exclude proximal aneurysms or arterial disease that is distal to the ankle. ${ }^{[8]}$

Clinical evaluation of intermittent claudication is mostly based on WHO/Rose questionnaire or the self-administered Edinburgh Claudication Questionnaire. ${ }^{[9,10]}$ Laboratory evaluation includes: complete blood count with platelet count, fasting glucose or A1C, fasting lipid profile, serum creatinine, and urinalysis for glucosuria and proteinuria ${ }^{[11]}$ beside this elevated levels homocysteine, C-reactive protein, and lipoprotein are risk factors for PVD. Duplex ultrasonography, magnetic resonance arteriography, and angiography are used to determine lesion localization, when invasive or surgical procedure is possible. ${ }^{[12]}$ PVD can be monitored by the degree of pain, walking distance, repeat $\mathrm{ABI}$ testing or evaluation by specialized center. Claudication may even progress to acute or critical limb ischemia; though the risk is less than $1 \%$ per year. ${ }^{[13]}$ Potent risk factors for PAD and IC are: Smoking, Hypertension, Diabetes, Lipid abnormalities, Increased LDL-cholesterol, Elevated triglycerides, HDL-cholesterol, Elevated homocysteine, Age, Increased fibrinogen and blood viscosity, sex , Lipoprotein(a), LDL (low-density lipoprotein) and HDL (high-density lipoprotein). Studies had shown a high degree of overlap between PAD and cardiovascular disease; the latter has been diagnosed in $29 \%$ of patients with PAD compared with only $11 \%$ without PAD.$^{[14]}$ Depending on the diagnostic technique used, cardiovascular disease can be detected in as many as $90 \%$ of patients with intermittent claudication. ${ }^{[15]}$ In a Swedish study of 439 men, an ankle-brachial index of less than 0.9 was associated with a 2.4 -fold higher mortality rate and a two folds higher cardiac event rate. ${ }^{[16]}$ Other studies also revealed up to 2-4 fold increase mortality risk in patients with intermittent claudication, predominantly from cardiovascular disease. ${ }^{[17]}$ The severity of IC symptoms is commonly scored by Rutherford-Baker's or Fontaine classification schemes. IC lesions are mostly located in the femoropopliteal arteries $(70 \%)$ with the remainder in the aortoiliac arteries. ${ }^{[18]}$

Age is the most important, nonmodifiable risk factor for PAD, with a prevalence of $0.9 \%$ in people under age 50 and $23.2 \%$ in people over the age of 80 . Ethnicity and sex is also important factors, with the highest prevalence of PAD seen in African American men and women (prevalence 19.2\%) and Hispanic women (prevalence 19.3\%). ${ }^{[19,20]}$ Prevalence of PAD in men is greater than women. Several important modifiable risk factors have also been greater identified. ${ }^{[21,22]}$ The association between smoking and PAD is unavoidable, the risk of PAD in smokers is proportional to the number of cigarettes consumed. ${ }^{[23,24]} \mathrm{PAD}$ is about twice as common in diabetic patients as it is in non-diabetics. Furthermore, for every $1 \%$ increase in hemoglobin-A1c, there is a $28 \%$ increased risk of developing PAD , beside this total cholesterol level greater than $270 \mathrm{mg} / \mathrm{dL}$, elevated ratio of total cholesterol to high-density lipoprotein (HDL), low HDL levels, and hypertriglyceridemia. Smoking magnifies the contribution of dyslipidemia in PAD ${ }^{[25]}$ Hypertension is associated with cardiovascular disease but is not as strong a risk factor for PAD as smoking and diabetes. In asymptomatic PAD patients, hypertension increases chance of developing symptoms. The increased risk is 2.5 -fold in men while in women it is 3.9-fold. ${ }^{[26,27]}$ In several studies dyslipidemia have been found to have an association with PAD and IC. Patients with renal disorders, especially postmenopausal women with a history of CAD, are found more susceptible to develop PAD than those with CAD who have normal renal function. ${ }^{[28,}$ ${ }^{29,30]}$. Hyperhomocysteinemia is a well known risk factor for both CAD and PAD, Its event among patients with vascular disease is quite higher than the general population, especially in young patients 
with PAD, $30 \%$ of whom have elevated homocysteine level .This is less intuitive but intriguing the association of C-reactive protein with $\mathrm{PAD} .^{[31,32]}$ Recent studies have shown that asymptomatic patients with high CRP level are more susceptible to develop symptomatic PAD over a period of 5year, than age-matched controls in whom CRP is not elevated. Among normal CRP level patients, those with a level is in the top quartile (of the normal range) are more susceptible to develop PAD as compared to those whose CRP level is in the bottom quartile (of the normal range). ${ }^{[33]}$

Common approaches to treatment of PAD and IC include: Modification of Life-style, Smoking cessation, Diet for weight loss and lipid altering, Supervised and unsupervised exercise programs, Pharmacotherapy, Re-vascularization, Endovascular treatment (PTA with or without Stanting) and Surgery Plus Co adjuvant Medical Treatment. Approved Risk-reducing agents are: Antiplatelet drugs(ie) aspirin, ticlopidine, clopidogrel, cilostazol and Lipid-altering drugs (ie) fibrates, niacin, statins (simvastatin, lovastatin, pravastatin, atorvastatin), bile acid sequestrants. Some of the Agents under study are: Propionyl-l-carnitine, prostaglandin drugs, angiogenic growth factors, 1-arginine. Approved drugs for treatment of intermittent claudication: Cilostazol, Pentoxifylline. The medical therapy for PAD is basically aimed to achieve increased walking distance, and secondary prevention of cardiovascular event.

Invasive therapy include: Endovascular treatment, PTA with balloon dilatation with or without stenting and Open Revascularization surgery. Medical treatment of patients with PAD has 2 objectives. The first is to improve the functional situation of the limb. Secondly, prevent events secondary to the multifocal distribution of the disease. Patients with symptomatic PAD are known to have a very poor long-term prognosis, with an increase risk of 10-year mortality, 15 times higher than patients without PAD ${ }^{[34]}$ Supervised programs of physical exercise has been proven highly effective and plays an important role in improvement Intermittent claudication. These programs also affect risk factors, endothelial function, and hemorrheologic markers. ${ }^{[35]}$

Surgical treatment (Conventional or endovascular) of PAD depends on the clinical situation of the patient and the vascular bed that requires reconstruction. It may need more than one surgical procedure depend on the sector of reconstruction. The indication for intervention should also include an evaluation of the particular surgical technique required revascularization surgery. Diffuse, extensive involvement is usually best treated by placement of an aortic unifemoral or bifemoral prosthesis (Figure 1,2). The effects of this well-systematized technique are variable. The results in terms of permeability are above $85 \%$ and $80 \%$ at 5 and 10 years, with operative mortality below $5 \%$. However, the technique involves major arterial surgery and requires quantifying the surgical risk to select the most suitable candidates.

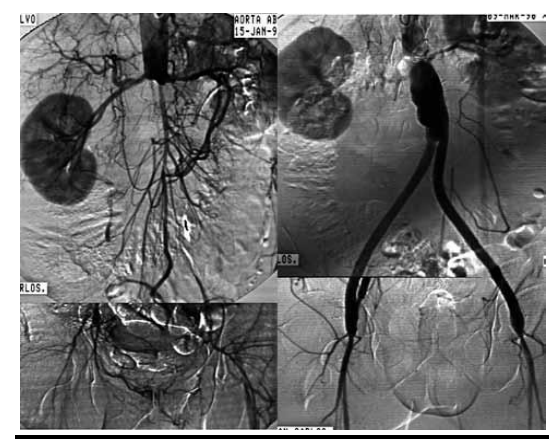

Figure1. Arteriography Showing Extensive Aortoiliac Occlusion and the Result after Aortobifemoral Bypass Surgery

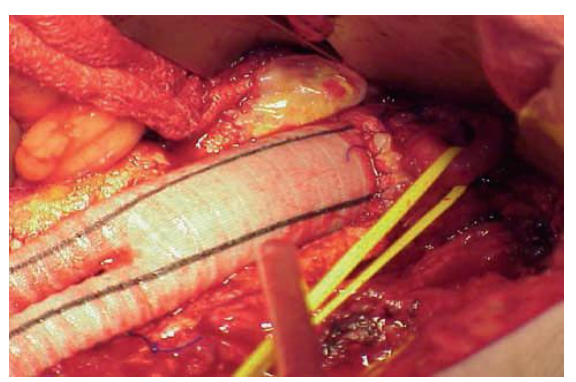

Figure2. Image of Dacron Prosthesis with Infrarenal Anastomosis 
Angioplasty_is the technique of mechanically widening of narrowed or obstructed arteries, initially described by Charles Dotter. Angioplasty provides the best results in short lesions, preferably stenosis and non-calcified lesions. Its long-term results in these situations are good, with permeability figures of $70 \%$ at 5 years for patients with claudication. ${ }^{[36]}$ The advantages of implanting a stent have been assessed in clinical trials, with comparatively better permeability figures in systematic stenting as compared with simple balloon angioplasty. ${ }^{[37,38,39]}$ The best approach is probably to implant a stent selectively in those patients in whom balloon angioplasty shows an initially suboptimal result (Figure 3). In general, we can say that short lesions, less than $10 \mathrm{~cm}$, preferably with stenosis, are the most suitable for endovascular treatment. ${ }^{[40,41,42,43]}$ In longer lesions, the use of expanded polytetrafluoroethylene coated stents seems to provide advantages over the other methods, though randomized studies with a greater follow-up are required ${ }^{[44]}$ In surgery plus combined with adjuvant medical treatment, prior to open or endovascular surgery an indefinite program of anti-aggregation is necessary. The use of anti-aggregating drugs has proved greater result in patients with a venous bypass as compared with prosthesis, especially in the infrainguinal region. ${ }^{[45]}$ In a Cochrane review, $41 \%$ reduced risk of graft occlusion was found (12 months of follow-up) in patients treated with acetylsalicylic acid following revascularization surgery. ${ }^{[46,47]}$ Although in patients with coronary disease double anti-aggregation is often used in accordance with the results obtained. However, no conclusive information is available regarding its usefulness in PAD.

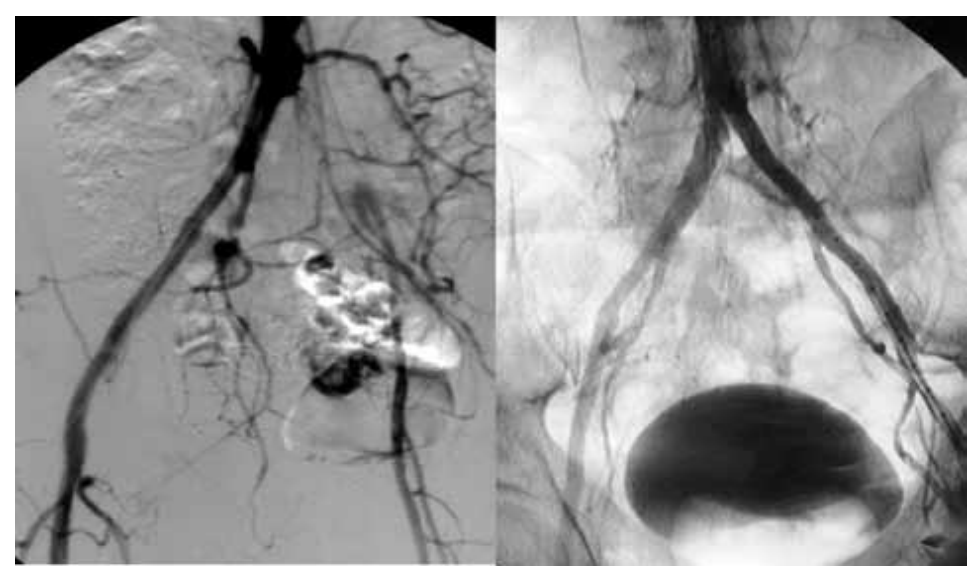

Figure3. Arteriographic Image of an Occlusion of the Primitive Iliac Artery and Stenosis of External Iliac Artery, Resolved by Implanting a Coated Stent

\section{DisCUSSION}

In order to decrease the incidence rate of perioperative complications and mortality, as well as the scope of anaesthesiological support and duration of in-hospital treatment and diminishing the operative wound all these goals can be achieved by means of minimally invasive interventions. PAD encompasses arterial disorders except the coronary vasculature, but in most guidelines it is limited to branches of the lower aorta. ${ }^{[48,49,50]}$ In compared to open surgical revascularization (Figure 5) for PAD, PTA is a better choice for the treatment infrainginual disease of critical limb ischemia, limited life expectancy, lack of an adequate venous conduit and multiple surgical comorbidities. ${ }^{[1,52]}$ Several studies have established lower peri-procedural mortality and morbidity and high technical success for PTA. Therefore infrapopliteal artery angioplasty is the "first line" therapeutic approach, particularly in high-risk critical limb ischemia (Figure 4) (CLI) patients. ${ }^{[53,54,55]}$ In diabetic patients extant and burden regarding infrapopliteal arterial diseases are well described in different literatures ${ }^{[5]}$, more over high post-PTA restenosis rates have also been consistently reported. ${ }^{[57,58,59]}$ The impact of high infrapopliteal vessel restenosis rates are not clear on the prognosis of CLI patients, despite regarding high infrapopliteal PTA restenosis rates, the limb salvage rates appear more acceptable ${ }^{[6]}$ when compared to open lower limb bypass. ${ }^{[61]}$ Thus, there is an evolving impression, endorsed by societal guidelines ${ }^{[62,63]}$ that favors potential near-term benefit of PTA as the "first line approach" in specific CLI patients in comparison to open surgery. Recent data suggest more distal target anastomosis in patients who experienced tibial PTA restenosis, subsequently underwent a lower limb bypass ${ }^{[64]}$ and had higher 1-year amputation and graft closure rates ${ }^{[65]}$ when compared to patients without prior PTA. Likewise, the BASIL trial investigators observed worse amputation-free survival (AFS) rates in patients undergoing bypass after a failed PTA than those undergoing primary bypass ${ }^{[66]}$ Long term follow up of CLI patients show high tibial PTA restenosis rates, that may require lower extremity 
bypass associated with higher bypass failure rates and worse outcomes. ${ }^{[67]}$ Paclitaxel drug-eluting balloons by reducing neointimal proliferation, promote arterial patency. In prospective clinical trials In relatively small CLI patient cohorts, tibial vessel drug-eluting balloon (DEB) angioplasty significantly reduced restenosis rates and late lumen loss (LLL) at 3, 6, and 12 months ${ }^{\left[{ }^{[6,69]}\right.}$ Although these angiographic assessments were not core lab adjudicated, there is a growing perception that the clinical results of DEB tibial angioplasty mirror the clinical experience in the superficial femoral artery. ${ }^{[70,71,72,73]}$ Ankle-brachial index (ABI) test is recommended screening test for early diagnosis of PAD in patients with signs and symptoms of lower extremity ischemia. An ABI $<0.9$ with values from 0.91 to 1.0 , consider as borderline abnormal. ${ }^{[7]} \mathrm{An} \mathrm{ABI}>1.0$ is normal, although $\mathrm{ABI}>1.4$ is typical in PAD patients with calcified, non-compressible lower extremity arteriopathy. The presentation, evaluation, and medical management of PAD are covered by earlier reviews and published guidelines by the American Heart Association and American College of Cardiology. ${ }^{75,76,77]}$ An ABI $<0.9$ requires close clinical surveillance because it is also an indication of other cardiovascular disease, require intensive secondary prevention measures and monitoring for the onset of symptoms, that may be gradual. ${ }^{[78,79]}$

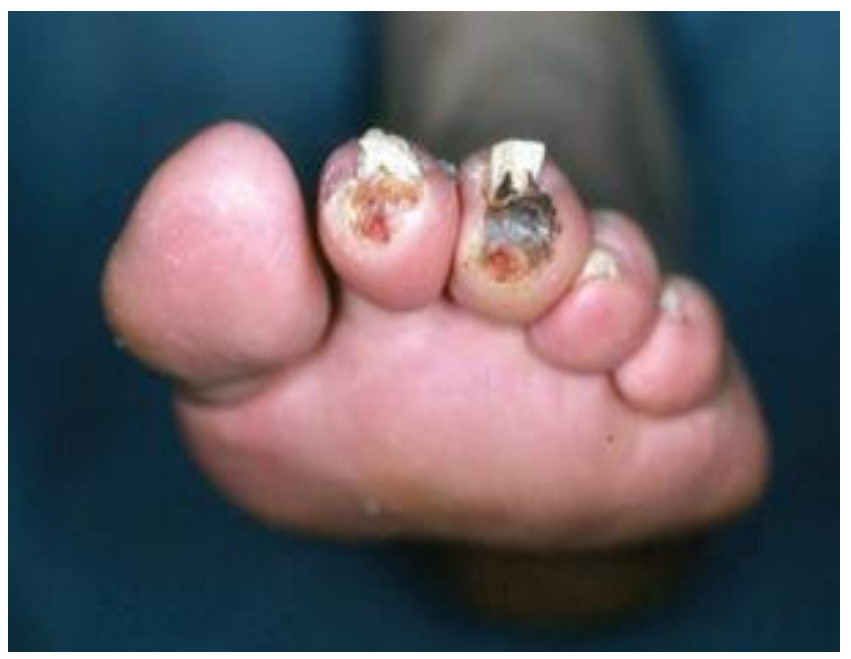

Figure4. Foot Wound Caused by Ischemic Rest Pain and Tissue Loss (Critical Limb Ischemia)

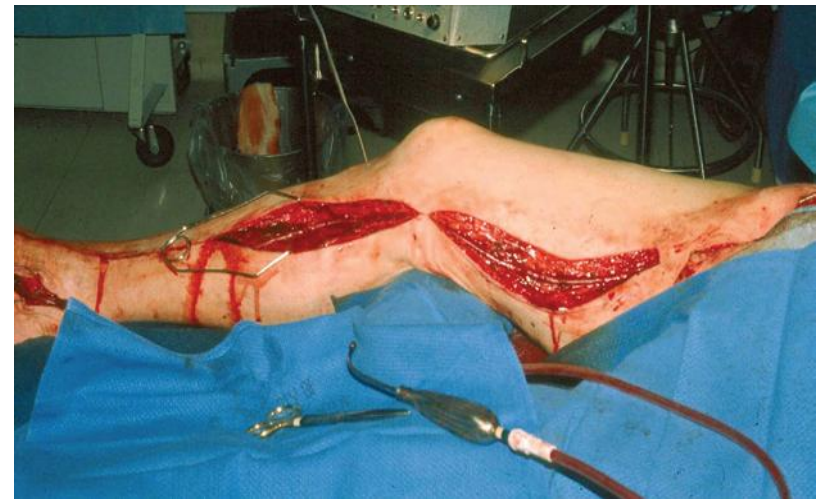

Figure5. An Intraoperative Photograph of a Right Femoral to Posterior Tibial Artery Bypass using the Greater Saphenous Vein to Correct Peripheral Arterial Disease

Technological improvements in endovascular revascularization equipments have increased options for complex lesions. Though, the longer lesions are more consistently associated with restenosis. ${ }^{[80]}$ For the low risk endovascular techniques, stents are an attractive and feasible treatment strategy. Surgical revascularization is preferred in the common femoral or popliteal arteries. Because these regions may increase stent fracture due to greater compression, torsion, and stretch associated with movement. A single-center series suggest treatment comprised of PTA with provisional stenting is associated with acceptable 12-month results. ${ }^{[81]}$ Endovascular approaches without stenting in these regions include atherectomy and balloon angioplasty alone. DCB with adjunctive atherectomy may address some issues associated with stent placement in these segments even though flow-limiting dissections, recalcitrant recoil, or residual disease would still limit this approach. ${ }^{[82]}$ 
Intermittent Claudication (IC) represents a progression of arterial obstruction caused by obstructive PAD causing ischemia. In contrast to both CLI and ALI the timing or need for revascularization in claudication is largely dictated by lifestyle limitation. Although IC patients are at low risk for limb loss, however diabetes increases this risk. ${ }^{[83,84,85]}$

In focal aortoiliac disease, it is proved that balloon angioplasty alone provides excellent long-term patency with provisional stent placement for good result. The Dutch Iliac Stent Trial comparing stenting with balloon angioplasty and provisional stenting resulted in comparable clinical outcomes, although this may have been caused by relatively low complexity Trans Atlantic Society Consensus. ${ }^{[86,87]}$ Due to increased recoil seen with ostial iliac disease, the use of primary stenting has been increased for aortoiliac disease. ${ }^{[88]}$ Primary stenting shows high patency rates in a meta-analysis study on 958 total patients suffering from more complex aortoiliac disease. ${ }^{[89]}$ Limitations of comparing different studies related to stenting for occlusive aortoiliac disease include i.e. complexity of disease, the differing segments of iliac artery to be treated, and the use of either balloon-expandable or self-expanding nitinol stents. ${ }^{[90,91]}$ Currently there are no randomized data available regarding comparing outcomes of aortoiliac stenting with these 2 types of stents. Self-expanding stents are good to avoid arterial rupture. The Cordis Randomized Iliac Stent Project (United States) trial showed same outcomes after iliac stenting with either nitinol or stainless steel self-expanding platforms. ${ }^{[92]}$ Restenosis remains the primary limitation of aortoiliac stenting. Experience derived from stenting with covered stents raised several concerns. Some studies regarding femoral and iliac arteries show similar rates of restenosis to non-covered stents at 12 months. ${ }^{[93,94]}$ Thrombotic occlusion of covered stents occurred in $10 \%$ of cases within 30 days of raising concerns over the long-term risks of stent thrombosis has been also reported. ${ }^{[95]}$ Covered stents do not solve the problem of restenosis, but shift its pattern to edge-restenosis especially in oversized stent. The Covered Versus Balloon-Expandable Stent Trial (COBEST) observe a higher patency rate with covered stent in comparison to non-covered stents in aortoiliac disease; however, non-covered stent group show unusually high restenosis rate. ${ }^{[96]}$ Balloon-expandable stents are mostly used to revascularize IC and isolated occlusive aortoiliac disease. "Self-Expanding Stents" are mostly made of Nitinol, it possess thermal shape memory and are more resilient to mechanical stresses by expanding on deployment at body temperature and then re-expanding after external radial compression. Recently, the Complete Self-Expanding trial that used a new Nitinol self-expanding stent to treat femoropopliteal disease demonstrated a low rate of target lesion revascularization (TLR) and no stent fractures at 12 months. The Supera Interwoven Nitinol Stent Outcomes in Above-Knee Interventions (SAKE) study also showed high rates of patency at 6 and 12 months with no stent fractures Furthermore, the outcomes after popliteal stenting with the Supera stent from the Leipzing Supera popliteal artery registry showed 6- and 12-month primary patency rates of $94.6 \%$ and $87.7 \%$, respectively, with a significant increase in mean ABI (0.58 versus $0.97 ; P<0.001)$ and no radiographic evidence of stent fracture at 15 months.

Restenosis remains one of the major limitations associated with long segments of SFA stenting, and stimulated the development of "drug-eluting stents". Recently, the Zilver PTX trial compared 24month outcomes between a self-expanding stent eluting paclitaxel to balloon angioplasty alone. ${ }^{[97]}$ Although this study had a high crossover rate to stenting in the balloon angioplasty arm, all the patients receiving bail-out stenting in this arm were randomized to drug-eluting stents (DES) or baremetal stents (BMS).In comparison with the angioplasty only, the primary DES group demonstrates higher primary patency with the DES $(74.8 \%$ versus $26.5 \%)$ at 2 years. The provisional DES group also demonstrates superior primary patency compared with the provisional BMS group $(83.4 \%$ versus $64.1 \%$ ). A French study of the budgetary impact of using the more costly Zilver PTX stent showed net cumulative savings of $€ 6807202$ over 5 years by reducing the need for future re-interventions. ${ }^{[98]}$ The use of "Covered self-expanding stents" for the obstructive femoropopliteal disease has been investigated to minimize the incidence of in-stent restenosis. An early trial of patients with symptomatic SFA disease randomized to either Viabahn stents or balloon angioplasty showed ultrasound-assessed primary patency (65\% versus $40 \%)$ and clinical improvement were better in the stent group. ${ }^{[99]}$ More recently, the Viabahn Endoprosthesis Versus Bare Nitinol Stent in the Treatment of Long Lesion Superficial Femoral Artery Occlusive Disease (VIBRANT) trial randomized patients with symptomatic complex lesions to Viabahn or conventional self-expanding stents and showed that ultrasound-assisted primary patency was low and not statistically different between the groups (53\% versus $58 \%$ at 12 months and $24.2 \%$ versus $25.9 \%$ at 36 months), despite higher stent fracture in the uncovered stent group (50\% versus $2 \%) .{ }^{[100]}$ 
A recent innovation "Drug-Coated Balloons" (DCBs) has potential benefits applicable to endovascular therapy. Preclinical validation studies have suggested that homogenously distributed drug delivery can be achieved with DCB. ${ }^{[101]}$

The Paclitaxel-Coated Balloons in Femoral Indication to Defeat Restenosis (PACIFIER) trial also demonstrated improved end points for DCB versus conventional angioplasty at 12 months. ${ }^{[102]}$ More recently, the Lutonix Paclitaxel-Coated Balloon for the Prevention of Femoropopliteal Restenosis (LEVANT I) trial demonstrated significantly decreased mean late lumen loss for de novo SFA disease treated with the lower paclitaxel dose Lutonix DCB versus conventional balloons in patients treated with either angioplasty only or after stenting. ${ }^{[103]}$ The Drug-Eluting Balloon in Peripheral Intervention for The Superficial Femoral Artery trial randomizing patients to upfront DCB or conventional angioplasty followed by stenting demonstrate similarly encouraging results at 12 months. ${ }^{[104]}$ Most studies of infrapopliteal revascularization include more CLI than IC patients, ${ }^{[105,106]}$ and IC alone is an uncommon indication. More recent trial data on infrapopliteal revascular-ization with DES are generally geared toward ascertaining important CLI outcomes rather than the relief of IC symptoms. The complexity of the infrapopliteal vasculature, and the technical demands of below-the-knee interventions, infrapopliteal revascularization is usually reserved for CLI only and is not currently recommended for the routine treatment of IC.

\section{Conclusion}

PTA and primary stenting of the lower limb vessels for management of atherosclerosis Obliterance can be performed safely in early and in advanced peripheral artery disease. The results seem to be an improvement over those of balloon angioplasty alone when compared with published literatures. In the intermediate term, treatment of peripheral artery disease by primary Implantation of a selfexpanding stent yielded results that were superior to those with the currently recommended approach of balloon angioplasty. This reduces the chance of re-occlusion and thus reduces the morbidity and provides a better patient outcome. In conclusion, PTA with stenting is a feasible, safe, and effective procedure for the treatment of CLI. Initial technical and clinical success rates were high, and procedural mortality and complication rates were low. In long-term results, most of the study data demonstrated a $76 \%$ assisted primary rate, an $80 \%$ secondary patency rate, and an $89 \%$ limb salvage rate at 5 years: the high limb salvage rate was attributed to the high assisted primary and secondary patency rates despite the low primary patency rate.

\section{REFERENCES}

[1] Hirsch AT, Criqui MH, Treat-Jacobson D, Regensteiner JG, Creager MA, Olin JW, et al. Peripheral arterial disease detection, awareness, and treatment in primary care. JAMA 2001; 286:1317-24.

[2] Hare AM, Glidden DV, Fox CS, Hsu CY. High prevalence of peripheral arterial disease in persons with renal insufficiency: results from the National Health and Nutrition Examination Survey 1999-2000. Circulation 2004; 109:320-3.

[3] Ridker PM, Stampfer MJ, Rifai N. Novel risk factors for systemic atherosclerosis: a comparison of C-reactive protein, fibrinogen, homocysteine, lipoprotein(a), and standard cholesterol screening as predictors of peripheral arterial disease. JAMA 2001; 285:2481-5.

[4] Stoffers HE, Kester AD, Kaiser V, Rinkens P, Knottnerus JA. Diagnostic value of signs and symptoms associated with peripheral arterial occlusive disease seen in general practice: a multivariable approach. Med Decis Making 1997; 17:61-70.

[5] Leng GC, Fowkes FG. The Edinburgh Claudication Questionnaire: an improved version of the WHO/Rose Questionnaire for use in epidemiological surveys. J Clin Epidemiol 1992; 45:11019.

[6] Ouriel K. Peripheral arterial desease. Lancet. 2001; 358:1257-64.

[7] Virmani R, Kolodgie FD, Burke AP, Farb A, Schwartz SM. Lesson from sudden coronary death: a comprehensive morphological classification scheme for therosclerotic lesions. Arterioscler Thromb Vasc Biol. 2000; 20:1262-75.

[8] Christensen JH, Freundlich M, Jacobsen BA, Falstie-Jensen N. Clinical relevance of pedal pulse palpation in patients suspected of peripheral arterial insufficiency. J Intern Med 1989; 226:95-9. 
[9] Fowkes FG, Housley E, Cawood EH, Macintyre CC, Ruckley CV, Prescott RJ. Edinburgh Artery Study. Prevalence of asymptomatic and symptomatic 448 JABFP November-December 2001 Vol. 14 No. 6 peripheral arterial disease in the general population. Int J Epidemiol 1991; 20:384-92.

[10] Leng GC, Fowkes FG. The Edinburgh Claudication Questionnaire: an improved version of the WHO/Rose Questionnaire for use in epidemiological surveys. J Clin Epidemiol 1992; 45:110109.

[11] TransAtlantic Intersociety Consensus (TASC). Management of peripheral arterial disease (PAD). Eur J Vasc Endovasc Surg 2000;19 (suppl A):S1-250.

[12] Burns P, Gough S, Bradbury AW. Management of peripheral arterial disease in primary care. BMJ 2003; 326:584-8.

[13] Dormandy J, Heeck L, Vig S. The natural history of claudication: risk to life and limb. Semin Vasc Surg 1999; 12:123-37.

[14] Criqui MH, Denenberg JO, Langer RD, FronekA. The epidemiology of peripheral arterial disease: importance of identifying the population at risk. Vasc Med 1997; 2:221-6.

[15] Management of peripheral arterial disease (PAD). Trans Atlantic Inter-Society Consensus (TASC) Working Group. J Vasc Surg 2000; 31 (1 Pt.2):S5-S14, S93-S101.

[16] Management of peripheral arterial disease (PAD). TransAtlantic Inter-Society Consensus (TASC) Working Group. J Vasc Surg 2000;31 (1 Pt.2):S5-S14, S93-S101.

[17] Kannel WB, McGee DL. Update on some epidemiologic features of intermittent claudication: the Framingham Study. J Am Geriatr Soc 1985; 33:13- 8.

[18] Zeller T. Current state of endovascular treatment of femoro-popliteal artery disease. Vasc Med. 2007; 12:223-234.10.1177/1358863X07079823 [PubMed: 17848483].

[19] Selvin E, Erlinger TP. Prevalence of and risk factors for peripheral arterial disease in the United States: results from the National Health and Nutrition Examination Survey, 1999-2000. Circulation. 2004;110 (6): 738-743.

[20] Norgren L, Hiatt WR, Dormandy JA, Nehler MR, Harris KA, Fowkes FG; TASC II Working Group. Inter-Society Consensus for the Management of Peripheral Arterial Disease (TASC II). J Vasc Surg. 2007;45:Suppl S: S5-S67.

[21] Norgren L, Hiatt WR, Dormandy JA, Nehler MR, Harris KA, Fowkes FG; TASC II Working Group. Inter-Society Consensus for the Management of Peripheral Arterial Disease (TASC II). J Vasc Surg. 2007; 45:Suppl S: S5-S67.

[22] Hirsch AT, Haskal ZJ, Hertzer NR, et al; American Association for Vascular Surgery; Society for Vascular Surgery; Society for Cardiovascular Angiography and Interventions; Society for Vascular Medicine and Biology; Society of Interventional Radiology; ACC/AHA Task Force on Practice Guidelines Writing Committee to Develop Guidelines for the Management of Patients With Peripheral Arterial Disease; American Association of Cardiovascular and Pulmonary Rehabilitation; National Heart, Lung, and Blood Institute; Society for Vascular Nursing; TransAtlantic Inter-Society Consensus; Vascular Disease Foundation. ACC/AHA 2005 Practice Guidelines for the management of patients with peripheral arterial disease (lower extremity, renal, mesenteric, and abdominal aortic): a collaborative report from the American Association for Vascular Surgery/Society for Vascular Surgery, Society for Cardiovascular Angiography and Interventions, Society for Vascular Medicine and Biology, Society of Interventional Radiology, and the ACC/AHA Task Force on Practice Guidelines (Writing Committee to Develop Guidelines for the Management of Patients With Peripheral Arterial Disease): endorsed by the American Association of Cardiovascular and Pulmonary Rehabilitation; National Heart, Lung, and Blood Institute; Society for Vascular Nursing; TransAtlantic Inter-Society Consensus; and Vascular Disease Foundation. Circulation. 2006; 113(11):e463-e654.

[23] Murabito JM, Evans JC, Larson MG, Nieto K, Levy D, Wilson PW; Framingham Study. The ankle-brachial index in the elderly and risk of stroke, coronary disease, and death: the Framingham Study. Arch Intern Med. 2003; 163(16):1939-1942.

[24] Fowkes GR, Housley E, Riemersa RA, et al. Smoking, lipids, glucose intolerance, and blood pressure as risk factors for peripheral atherosclerosis compared with ischemic heart disease in the Edinburgh Artery Study. Am J Epidemiol. 1992; 135(4):331-340. 
[25] Selvin E, Marinopoulos S, Berkenblit G, et al. Meta-analysis: glycosylated hemoglobin and cardiovascular disease in diabetes mellitus. Ann Intern Med. 2004; 141(6):421-431.

[26] Selvin E, Marinopoulos S, Berkenblit G, et al. Meta-analysis: glycosylated hemoglobin and cardiovascular disease in diabetes mellitus. Ann Intern Med. 2004; 141(6):421-431.

[27] Murabito JM, D’Agostino RB, Silbershatz H, Wilson WF. Intermittent claudication. A risk profile from The Framingham Heart Study. Circulation. 1997; 96(1):44-49.

[28] Norgren L, Hiatt WR, Dormandy JA, Nehler MR, Harris KA, Fowkes FG; TASC II Working Group. Inter-Society Consensus for the Management of Peripheral Arterial Disease (TASC II). J Vasc Surg. 2007; 45:Suppl S: S5-S67.

[29] Hirsch AT, Haskal ZJ, Hertzer NR, et al; American Association for Vascular Surgery; Society for Vascular Surgery; Society for Cardiovascular Angiography and Interventions; Society for Vascular Medicine and Biology; Society of Interventional Radiology; ACC/AHA Task Force on Practice Guidelines Writing Committee to Develop Guidelines for the Management of Patients With Peripheral Arterial Disease; American Association of Cardiovascular and Pulmonary Rehabilitation; National Heart, Lung, and Blood Institute; Society for Vascular Nursing; TransAtlantic Inter-Society Consensus; Vascular Disease Foundation. ACC/AHA 2005 Practice Guidelines for the management of patients with peripheral arterial disease (lower extremity, renal, mesenteric, and abdominal aortic): a collaborative report from the American Association for Vascular Surgery/Society for Vascular Surgery, Society for Cardiovascular Angiography and Interventions, Society for Vascular Medicine and Biology, Society of Interventional Radiology, and the ACC/AHA Task Force on Practice Guidelines (Writing Committee to Develop Guidelines for the Management of Patients With Peripheral Arterial Disease): endorsed by the American Association of Cardiovascular and Pulmonary Rehabilitation; National Heart, Lung, and Blood Institute; Society for Vascular Nursing; TransAtlantic Inter-Society Consensus; and Vascular Disease Foundation. Circulation. 2006; 113(11):e463-e654.

[30] O'Hare AM, Vittinghoff E, Hsia J, Shlipak MG. Renal insufficiency and the risk of lower extremity peripheral arterial disease:results from the Heart and Estrogen/Progestin Replacement Study (HERS). J Am Soc Nephrol. 2004; 15 (4):1046-1051].

[31] Norgren L, Hiatt WR, Dormandy JA, Nehler MR, Harris KA, Fowkes FG; TASC II Working Group. Inter-Society Consensus for the Management of Peripheral Arterial Disease (TASC II). J Vasc Surg. 2007; 45: Suppl S: S5-S67.

[32] Ridker PM, Stampfer MJ, Rifai N. Novel risk factors for systemic atherosclerosis: a comparison of C-reactive protein, fibrinogen, homocysteine, lipoprotein(a), and standard cholesterol screening as predictors of peripheral arterial disease. JAMA. 2001; 285(19):2481-2485.

[33] Ridker PM, Stampfer MJ, Rifai N. Novel risk factors for systemic atherosclerosis: a comparison of C-reactive protein, fibrinogen, homocysteine, lipoprotein(a), and standard cholesterol screening as predictors of peripheral arterial disease. JAMA. 2001;285(19):2481-2485.

[34] Criqui MH, Langer RD, Fronek A, Feigelson HS, Klauber MR, McCann TJ, et al. Mortality over a period of 10 years in patiens with peripheral arterial disease. N Engl J Med. 1992; 326:381-6.

[35] Arosio E, Minuz P, Prior M, Zuliani V, Gaino S, de Marchi S, et al. Vascular adhesion molecule-1 and markers of platelet function before and after a treatment with iloprost or a supervised physical exercise program in patients with peripheral arterial disease. Life Sci. 2001; 69:421-33.

[36] Rutherford R, Durham J. Percutaneous ballon angioplasty for arteriosclerosis obliterans: long term results. En: Yao J, Pearce W, editors. Techniques in vascular surgery. Philadelphia: Saunders; 1992. p. 329-45.

[37] Tetteroo E, van Der Graaf Y, Bosch JL, van Engelen AD, Hunink MG, Eikelboom BC, et al. Randomised comparison of primary stent placement versus primary angioplasty followed by selective stent placement in patients with iliac-artery occlusive disease. Dutch Iliac Stent Trial Study Group. Lancet. 1998; 351:1153-9.

[38] Bosch JL, Hunink MG. Meta-analysis of the results of percutaneous transluminal angioplasty and stent placement for aortoiliac occlusive disease. Radiology. 1997; 204:87-96. 
[39] de Vries S, Hunink M. Results of aortic bifurcation grafts for aortoiliac occlusive disease: a meta-analysis. J Vasc Surg. 1997; 26:558-69.

[40] Cejna M, Thurnher S, Illiasch H, Horvath W, Waldenberger P, Hornik K, et al. PTA versus Palmaz stent placement in femoropopliteal artery obstructions: a multicenter prospective randomized study. J Vasc Interv Radiol. 2001; 12:23-31.

[41] Grimm J, Muller-Hulsbeck S, Jahnke T, Hilbert C, Brossmann J, Heller M. Randomized study to compare PTA alone versus PTA with Palmaz stent placement for femoropopliteal lesions. J Vasc Interv Radiol. 2001; 12:935-42.

[42] Vroegindeweij D, Vos L, Tielbeek A, Buth J, van Der Bosch H. Balloon angioplasty combined with primary stenting versus balloon angioplasty alone in femoropopliteal obstructions: a comparative randomized study. Cardiovasc Intervent Radiol. 1997; 20:420-5.

[43] Schillinger M, Sabeti S, Loewe C, Dick P, Amighi J, Mlekusch W, et al. Balloon angioplasty versus implantation of nitinol stents in the superficial femoral artery. N Engl J Med. 2006; 354:1879-88.

[44] Kedora J, Hohmann S, Garrett W, Munschaur C, Theune B. Randomized comparison of percutaneous Viabahn stent grafts vs prosthetic femoral-popliteal bypass in the treatment of superficial femoral arterial occlusive disease. J Vasc Surg. 2007; 45:10-6.

[45] Tangelder M, Lawson J, Algra A, Eikelboom B. Systematic review of randomized controlled trials of aspirin and oral anticoagulants in prevention of graft occlusion and ischemic events after infrainguinal bypass surgery. J Vasc Surg. 1999; 30:701-9.

[46] Dorffler-Melly J, Koopman MM, Adam DJ, Buller HR, Prins MH. Antiplatelet agents for preventing thrombosis after peripheral arterial bypass surgery. Cochrane Database Syst Rev. 2003:CD000535.

[47] Dorffler-Melly J, Buller H, Koopman M, Adam D, Prins M. Antithrombotic agents for preventing thrombosis after peripheral bypass surgery. Cochrane Database Syst Rev. 2003:CD000536.

[48] Rooke TW, Hirsch AT, Misra S, et al. 2011 ACCF/AHA Focused Update of the Guideline for the Management of Patients With Peripheral Artery Disease (Updating the 2005 Guideline): a report of the American College Of Cardiology Foundation/American Heart Association Task Force on Practice Guidelines. Circulation. 2011; 124:2020-2045. [PubMed: 21959305.

[49] Hirsch AT, Haskal ZJ, Hertzer NR, et al. American Association for Vascular Surgery; Society for Vascular Surgery; Society for Cardiovascular Angiography and Interventions; Society for Vascular Medicine and Biology; Society of Interventional Radiology; ACC/AHA Task Force on Practice Guidelines Writing Committee to Develop Guidelines for the Management of Patients With Peripheral Arterial Disease; American Association of Cardiovascular and Pulmonary Rehabilitation; National Heart, Lung, and Blood Institute; Society for Vascular Nursing; TransAtlantic Inter-Society Consensus; Vascular Disease Foundation. ACC/AHA 2005 Practice Guidelines for the management of patients with peripheral arterial disease (lower extremity, renal, mesenteric, and abdominal aortic): a collaborative report from the American Association for Vascular Surgery/Society for Vascular Surgery, Society for Cardiovascular Angiography and Interventions, Society for Vascular Medicine and Biology, Society of Interventional Radiology, and the ACC/AHA Task Force on Practice Guidelines (Writing Committee to Develop Guidelines for the Management of Patients With Peripheral Arterial Disease): endorsed by the American Association of Cardiovascular and Pulmonary Rehabilitation; National Heart, Lung, and Blood Institute; Society for Vascular Nursing; TransAtlantic Inter-Society Consensus; and Vascular Disease Foundation. Circulation. 2006; 113:e463-e654.10.1161/CIRCULA TION AHA.106.174526 [PubMed: 16549646].

[50] Wennberg PW. Approach to the patient with peripheral arterial disease. Circulation. 2013; 128:2241-2250.10.1161/CIRCULATIONAHA.113.000502 [PubMed: 24218439].

[51] Beard JD: Which is the best revascularization for critical limb ischemia: endovascular or open surgery? J Vasc Surg 2008, 48:112-116S. \#\# Blevins WA Jr, Schneider PA: Endovascular management of critical limb ischemia. Eur J Vasc Endovasc Surg 2010, 39(6):756-761.

[52] Adam DJ, Beard JD, Cleveland T, Bell J, Bradbury AW, Forbes JF, Fowkes FG, Gillepsie I, Ruckley CV, Raab G, Storkey H: BASIL trial participants. Bypass versus angioplasty in severe ischaemia of the leg (BASIL): multicenter, randomised controlled trial. Lancet 2005, 366(9501):1925-1934. 
[53] Conrad MF, Kang J, Cambria RP, Brewster DC, Watkins MT, Kwolek CJ, LaMuraglia GM: Infrapopliteal balloon angioplasty for the treatment of chronic occlusive disease. J Vasc Surg 2009, 50(4):799-805.

[54] Söderström M, Arvela E, Venermo M, Lepäntalo M, Albäck A: Tertiary patency as a measure of active revascularization policy for leg salvage. Ann Vasc Surg 2011, 25(2):159-164. 6. Kudo T, Chandra FA, Ahn SS: The effectiveness of percutaneous transluminal angioplasty for the treatment of critical limb ischemia: a 10-year experience. J Vasc Surg 2005, 41(3):423-435.

[55] Haider SN, Kavanagh EG, Forlee M, Colgan MP, Madhavan P, Moore DJ, Shanik GD: Twoyear outcome with preferential use of infrainguinal angioplasty for critical ischemia. J Vasc Surg 2006, 43:504-512.

[56] Graziani L, Silvestro A, Bertone V, Manara E, Andreini R, Sigala A, Mingardi R, De Giglio R: Vascular involvement in diabetic subjects with ischemic foot ulcer: a new morphologic categorization of disease severity. Eur J Vasc Endovasc Surg 2007, 33(4):453-460.

[57] Parsons RE, Suggs WD, Lee JJ, Sanchez LA, Lyon RT, Veigh FJ: Percutaneous transluminal angioplasty for the treatment of limb threatening ischemia: do the results justify an attempt before bypass grafting? J Vasc Surg 1998, 28:1066-1071.

[58] Schmidt A, Ulrich M, Winkler B, Klaeffling C, Bausback Y, Bräunlich S, BotsiosbS, Kruse HJ, Varcoe RL, Kum S, Scheinert D: Angiographic patency and clinical outcome after balloonangioplasty for extensive infrapopliteal arterial disease. Catheter Cardiovasc Interv 2010, 76(7):1047-1054.

[59] Baumann F, Willenberg T, Do DD, Keo HH, Baumgartner I, Diehm N: Endovascular revascularization of below-the-knee arteries: prospective short-term angiographic and clinical follow-up. J Vasc Interv Radiol 2011,22(12):1073-1665.

[60] S, Kruse HJ, Varcoe RL, Kum S, Scheinert D: Angiographic patency and clinical outcome after balloon-angioplasty for extensive infrapopliteal arterial disease. Catheter Cardiovasc Interv 2010, 76(7):1047-1054.

[61] Romiti M, Albers M, Brochado-Neto FC, Durazzo AE, Pereira CA, De Luccia N:Meta-analysis of infrapopliteal angioplasty for chronic critical limb ischemia. J Vasc Surg 2008, 47(5):975981.

[62] Adam DJ, Bradbury AW: TASC II document on the management of peripheral arterial disease. Eur J Vasc Endovasc Surg 2007, 33(1):1-2.

[63] Hirsch AT, Haskal ZJ, Hertzer NR, Bakal CW, Creager MA, Halperin JL, Hiratzka LF, Murphy WR, Olin JW, Puschett JB, Rosenfield KA, Sacks D, Stanley JC, Taylor LM Jr, White CJ, White J, White RA, Antman EM, Smith SC Jr, Adams CD, Anderson JL, Faxon DP, Fuster V, Gibbons RJ, Hunt SA, Jacobs AK, Nishimura R, Ornato JP, Page RL, Riegel B, et al: ACC/AHA 2005 Practice Guidelines for the management of patients with peripheral arterial disease (lower extremity, renal, mesenteric, and abdominal aortic): a collaborative report from the American Association for Vascular Surgery/ Society for Vascular Surgery, Society for Cardiovascular Angiography and Interventions, Society for Vascular Medicine and Biology, Society of Interventional Radiology, and the ACC/AHA Task Force on Practice Guidelines (Writing Committee to Develop Guidelines for the Management of Patients With Peripheral Arterial Disease): endorsed by the American Association of Cardiovascular and Pulmonary Rehabilitation; National Heart, Lung, and Blood Institute; Society for Vascular Nursing; TransAtlantic Inter-Society Consensus; and Vascular Disease Foundation. Circulation 2006, 113(11):e463-e654.

[64] Conte MS: Diabetic revascularization: endovascular versus open bypass-do we have the answer? Semin Vasc Surg 2012, 25(2):108-114.

[65] Nolan BW, De Martino RR, Stone DH, Schanzer A, Goodney PP, Walsh DW, Cronenwett JL, Vascular Study Group of New England: Prior failed cipsilateral percutaneous endovascular intervention in patients with critical limb ischemia predicts poor outcome after lower extremity bypass. J Vasc Surg 2011, 54(3):730-735.

[66] Adam DJ, Beard JD, Cleveland T, Bell J, Bradbury AW, Forbes JF, Fowkes FG, Gillepsie I, Ruckley CV, Raab G, Storkey H: BASIL trial participants. Bypass versus angioplasty in severe ischaemia of the leg (BASIL): multicenter, randomised controlled trial. Lancet 2005, 366(9501):1925-1934. 
[67] Nolan BW, De Martino RR, Stone DH, Schanzer A, Goodney PP, Walsh DW, Cronenwett JL, Vascular Study Group of New England: Prior failed ipsilateral percutaneous endovascular intervention in patients with critical limb ischemia predicts poor outcome after lower extremity bypass. J Vasc Surg 2011, 54(3):730-735.

[68] Schmidt A, Piorkowski M, Werner M, Ulrich M, Bausback Y, Bräunlich S, Ick H, Schuster J, Botsios S, Kruse HJ, Varcoe RL, Scheinert D: First experience with drug-eluting balloons in infrapopliteal arteries: restenosis rate and clinical outcome. J Am Coll Cardiol 2011, 58(11):1105-1109.

[69] Fanelli F, Cannavale A, Boatta E, Corona M, Lucatelli P, Wlderk A, Cirelli C, Salvatori FM: Lower limb multilevel treatment with drug-eluting balloons: 6-month results from the DEBELLUM randomized trial. J Endovasc Ther 2012, 19(5):571-580.

[70] claudicants [Tepe G, Zeller T, Albrecht T, Heller S, Schwarzwälder U, Beregi JP, Claussen CD, Oldenburg A, Scheller B, Speck U: Local delivery of paclitaxel to inhibit restenosis during angioplasty of the leg. N Engl J Med 2008, 358(7):689-699.

[71] Werk M, Langner S, Reinkensmeier B, Boettcher HF, Tepe G, Dietz U, Hosten N, Hamm B, Speck U, Ricke J: Inhibition of restenosis in femoropopliteal arteries: paclitaxel-coated versus uncoated balloon: femoral paclitaxel randomized pilot trial. Circulation 2008, 118(13):13581365 .

[72] Werk M, Albrecht T, Meyer DR, Ahmed MN, Behne A, Dietz U, Eschenbach G, Hartmann H, Lange C, Schnorr B, Stiepani H, Zoccai GB, Hänninen EL: Paclitaxel-coated balloons reduce restenosis after femoro-popliteal angioplasty: evidence from the randomized PACIFIER trial. Circ Cardiovasc Interv 2012, 5(6):831-840.

[73] Micari A, Cioppa A, Vadalà G, Castriota F, Liso A, Marchese A, Grattoni C, Pantaleo P, Cremonesi A, Rubino P, Biamino G: 2-year results of paclitaxeleluting balloons for femoropopliteal artery disease: evidence from a multicenter registry. JACC Cardiovasc Interv 2013, 6(3):282-289.

[74] Aboyans V, Criqui MH, Abraham P, et al. American Heart Association Council on Peripheral Vascular Disease; Council on Epidemiology and Prevention; Council on Clinical Cardiology; Council on Cardiovascular Nursing; Council on Cardiovascular Radiology and Intervention, and Council on Cardiovascular Surgery and Anesthesia. Measurement and interpretation of the ankle-brachial index: a scientific statement from the American Heart Association. Circulation. 2012; 126:2890-2909.10.1161/CIR.0b013e318276fbcb [PubMed: 23159553].

[75] Rooke TW, Hirsch AT, Misra S, et al. 2011 ACCF/AHA Focused Update of the Guideline for the Management of Patients With Peripheral Artery Disease (Updating the 2005 Guideline): a report of the American College Of Cardiology Foundation/American Heart Association Task Force on Practice Guidelines. Circulation. 2011; 124:2020-2045. [PubMed: 21959305].

[76] Hirsch AT, Haskal ZJ, Hertzer NR, et al. American Association for Vascular Surgery; Society for Vascular Surgery; Society for Cardiovascular Angiography and Interventions; Society for Vascular Medicine and Biology; Society of Interventional Radiology; ACC/AHA Task Force on Practice Guidelines Writing Committee to Develop Guidelines for the Management of Patients With Peripheral Arterial Disease; American Association of Cardiovascular and Pulmonary Rehabilitation; National Heart, Lung, and Blood Institute; Society for Vascular Nursing; TransAtlantic Inter-Society Consensus; Vascular Disease Foundation. ACC/AHA 2005 Practice Guidelines for the management of patients with peripheral arterial disease (lower extremity, renal, mesenteric, and abdominal aortic): a collaborative report from the American Association for Vascular Surgery/Society for Vascular Surgery, Society for Cardiovascular Angiography and Interventions, Society for Vascular Medicine and Biology, Society of Interventional Radiology, and the ACC/AHA Task Force on Practice Guidelines (Writing Committee to Develop Guidelines for the Management of Patients With Peripheral Arterial Disease): endorsed by the American Association of Cardiovascular and Pulmonary Rehabilitation; National Heart, Lung, and Blood Institute; Society for Vascular Nursing; TransAtlantic Inter-Society Consensus; and Vascular Disease Foundation. Circulation. 2006; 113:e463-e654.10.1161/ CIRCULATIO NAHA.106.174526 [PubMed: 16549646]

[77] Wennberg PW. Approach to the patient with peripheral arterial disease. Circulation. 2013; 128:2241-2250.10.1161/CIRCULATIONAHA.113.000502 [PubMed: 24218439]. 
[78] Rooke TW, Hirsch AT, Misra S, et al. 2011 ACCF/AHA Focused Update of the Guideline for the Management of Patients With Peripheral Artery Disease (Updating the 2005 Guideline): a report of the American College Of Cardiology Foundation/American Heart Association Task Force on Practice Guidelines. Circulation. 2011; 124:2020-2045. [PubMed: 21959305].

[79] Norgren L, Hiatt WR, Dormandy JA, Nehler MR, Harris KA, Fowkes FG, Rutherford RB. TASC II Working Group. Inter-society consensus for the management of peripheral arterial disease. Int Angiol. 2007; 26:81-157. [PubMed: 17489079].

[80] Connors G, Todoran TM, Engelson BA, Sobieszczyk PS, Eisenhauer AC, Kinlay S. Percutaneous revascularization of long femoral artery lesions for claudication: patency over 2.5 years and impact of systematic surveillance. Catheter Cardiovasc Interv. 2011; 77:10551062.10.1002/ccd.22802 [PubMed: 20853355].

[81] Bonvini RF, Rastan A, Sixt S, Noory E, Schwarz T, Frank U, Roffi M, Dorsaz PA, Schwarzwälder U, Bürgelin K, Macharzina R, Zeller T. Endovascular treatment of common femoral artery disease: medium-term outcomes of 360 consecutive procedures. J Am Coll Cardiol. 2011; 58:792-798.10.1016/j.jacc.2011.01.070 [PubMed: 21835313].

[82] Scheinert D, Duda S, Zeller T, Krankenberg H, Ricke J, Bosiers M, Tepe G, Naisbitt S, Rosenfield K. The LEVANT I (Lutonix paclitaxel-coated balloon for the prevention of femoropopliteal restenosis) trial for femo-ropopliteal revascularization: first-in-human randomized trial of low-dose drug-coated balloon versus uncoated balloon angioplasty. JACC Cardiovasc Interv. 2014; 7:10-19.10.1016/j.jcin.2013.05.022 [PubMed: 24456716].

[83] Kannel WB, Skinner JJ Jr, Schwartz MJ, Shurtleff D. Intermittent claudication. Incidence in the Framingham Study. Circulation. 1970; 41:875-883. [PubMed: 5444530].

[84] Muluk SC, Muluk VS, Kelley ME, Whittle JC, Tierney JA, Webster MW, Makaroun MS. Outcome events in patients with claudication: A 15-year study in 2777 patients. J Vasc Surg. 2001; 33:251-257. Discussion 257-258. [PubMed: 11174775].

[85] Aquino R, Johnnides C, Makaroun M, Whittle JC, Muluk VS, Kelley ME, Muluk SC. Natural history of claudication: long-term serial follow-up study of 1244 claudicants. J Vasc Surg. 2001; 34:962-970.10.1067/mva.2001.119749 [PubMed: 11743546].

[86] Tetteroo E, van der Graaf Y, Bosch JL, van Engelen AD, Hunink MG, Eikelboom BC, Mali WP. Randomised comparison of primary stent placement versus primary angioplasty followed by selective stent placement in ar patients with iliac-artery occlusive disease. Dutch Iliac Stent Trial Study Group. Lancet. 1998; 351:1153-1159. [PubMed: 9643685].

[87] Klein WM, van der Graaf Y, Seegers J, Spithoven JH, Buskens E, van Baal JG, Buth J, Moll FL, Overtoom TT, van Sambeek MR, Mali WP. Dutch iliac stent trial: long-term results in patients randomized for primary or selective stent placement. Radiology. 2006; 238:734744.10.1148/radiol.2382041053 [PubMed: 16371580].

[88] AbuRahma AF, Hayes JD, Flaherty SK, Peery W. Primary iliac stenting versus transluminal angioplasty with selective stenting. J Vasc Surg. 2007; 46:965-970.10.1016/j.jvs.2007.07.027 [PubMed: 17905559].

[89] Saltzman AJ, Stone GW, Claessen BE, et al. Long-term impact of chronic kidney disease in patients with ST-segment elevation myocardial infarction treated with primary percutaneous coronary intervention: the HORIZONS-AMI (Harmonizing Outcomes With Revascularization and Stents in Acute Myocardial Infarction) trial. JACC Cardiovasc Interv. 2011; 4:10111019.10.1016/j.jcin.2011.06.012 [PubMed: 21939942].

[90] AbuRahma AF, Hayes JD, Flaherty SK, Peery W. Primary iliac stenting versus transluminal angioplasty with selective stenting. J Vasc Surg. 2007; 46:965-970.10.1016/j.jvs.2007.07.027 [PubMed: 17905559].

[91] Goode SD, Cleveland TJ, Gaines PA. STAG Trial Collaborators. Randomized clinical trial of stents versus angioplasty for the treatment of iliac artery occlusions (STAG trial). Br J Surg. 2013; 100:1148-1153.10.1002/bjs.9197 [PubMed: 23842828].

[92] Ponec D, Jaff MR, Swischuk J, Feiring A, Laird J, Mehra M, Popma JJ, Donohoe D, Firth B, Keim E, Snead D. CRISP Study Investigators. The Nitinol SMART stent vs Wallstent for suboptimal iliac artery angioplasty: CRISP-US trial results. J Vasc Interv Radiol. 2004; 15:911918.10.1097/01.RVI.0000140935.45313.35 [PubMed: 15361558]. 
[93] Wiesinger B, Beregi JP, Oliva VL, Dietrich T, Tepe G, Bosiers M, Hüttl K, Müller-Hülsbeck S, Bray A, Tielemans H, Duda SH. PTFE-covered self-expanding nitinol stents for the treatment of severe iliac and femoral artery stenoses and occlusions: final results from a prospective study. J Endovasc Ther. 2005; 12:240-246.10.1583/04-1327MR.1 [PubMed: 15823072].

[94] Lammer J, Dake MD, Bleyn J, Katzen BT, Cejna M, Piquet P, Becker GJ, Settlage RA. Peripheral arterial obstruction: prospective study of treatment with a transluminally placed selfexpanding stent-graft. International Trial Study Group. Radiology. 2000; 217:95104.10.1148/radiology.217.1.r00se0595 [PubMed: 11012429].

[95] Fischer M, Schwabe C, Schulte KL. Value of the hemobahn/viabahn endoprosthesis in the treatment of long chronic lesions of the superficial femoral artery: 6 years of experience. $\mathrm{J}$ Endovasc Ther. 2006; 13:281-290.10.1583/05-1799.1 [PubMed: 16784314].

[96] Mwipatayi BP, Thomas S, Wong J, Temple SE, Vijayan V, Jackson M, Burrows SA. Covered Versus Balloon Expandable Stent Trial (COBEST) Co-Investigators. A comparison of covered vs bare expandable stents for the treatment of aortoiliac occlusive disease. J Vasc Surg. 2011; 54:1561-1570.10.1016/j.jvs.2011.06.097 [PubMed: 21906903].

[97] Dake MD, Ansel GM, Jaff MR, Ohki T, Saxon RR, Smouse HB, Snyder SA, O'Leary EE, Tepe G, Scheinert D, Zeller T. Zilver PTX Investigators. Sustained safety and effectiveness of paclitaxel-eluting stents for femoropopliteal lesions: 2-year follow-up from the Zilver PTX randomized and single-arm clinical studies. J Am Coll Cardiol. 2013; 61:24172427.10.1016/j.jacc.2013.03.034 [PubMed: 23583245].

[98] De Cock E, Sapoval M, Julia P, de Lissovoy G, Lopes S. A budget impact model for paclitaxeleluting stent in femoropopliteal disease in France. Cardiovasc Intervent Radiol. 2013; 36:362370.10.1007/s00270-012-0494-x [PubMed: 23073560].

[99] Saxon RR, Dake MD, Volgelzang RL, Katzen BT, Becker GJ. Randomized, multicenter study comparing expanded polytetrafluoroethylene-covered endoprosthesis placement with percutaneous transluminal angioplasty in the treatment of superficial femoral artery occlusive disease. J Vasc Interv Radiol. 2008; 19:823-832.10.1016/j.jvir.2008.02.008 [PubMed: 18503895].

[100] Geraghty PJ, Mewissen MW, Jaff MR, Ansel GM. VIBRANT Investigators. Three-year results of the VIBRANT trial of VIABAHN endoprosthesis versus bare nitinol stent implantation for complex superficial femoral artery occlusive disease. J Vasc Surg. 2013; 58:386-95. e4. 10.1016/j.jvs.2013.01.050 [PubMed: 23676191].

[101] Speck U, Scheller B, Abramjuk C, Breitwieser C, Dobberstein J, Boehm M, Hamm B. Neointima inhibition: comparison of effectiveness of non-stent-based local drug delivery and a drug-eluting stent in porcine coronary arteries. Radiology. 2006; 240:411-418.10.1148/ radiol.2402051248 [PubMed: 16864669].

[102] Werk M, Albrecht T, Meyer DR, Ahmed MN, Behne A, Dietz U, Eschenbach G, Hartmann H, Lange C, Schnorr B, Stiepani H, Zoccai GB, Hänninen EL. Paclitaxel-coated balloons reduce restenosis after femoro-popliteal angioplasty: evidence from the randomized PACIFIER trial. Circ Cardiovasc Interv. 2012; 5:831-840.10.1161/ CIRCINTERVENTIONS.112.971630 [PubMed: 23192918].

[103] Scheinert D, Duda S, Zeller T, Krankenberg H, Ricke J, Bosiers M, Tepe G, Naisbitt S, Rosenfield K. The LEVANT I (Lutonix paclitaxel-coated balloon for the prevention of femoropopliteal restenosis) trial for femo-ropopliteal revascularization: first-in-human randomized trial of low-dose drug-coated balloon versus uncoated balloon angioplasty. JACC Cardiovasc Interv. 2014; 7:10-19.10.1016/j.jcin.2013.05.022 [PubMed: 24456716].

[104] Liistro F, Grotti S, Porto I, Angioli P, Ricci L, Ducci K, Falsini G, Ventoruzzo G, Turini F, Bellandi G, Bolognese L. Drug-eluting balloon in peripheral intervention for the superficial femoral artery: the DEBATE-SFA randomized trial (drug eluting balloon in peripheral intervention for the superficial femoral artery). JACC Cardiovasc Interv. 2013; 6:12951302.10.1016/j.jcin.2013.07.010 [PubMed: 24239203].

[105] Bosiers M, Hart JP, Deloose K, Verbist J, Peeters P. Endovascular therapy as the primary approach for limb salvage in patients with critical limb ischemia: experience with 443 infrapopliteal procedures. Vascular. 2006; 14:63-69. [PubMed: 16956473].

[106] Kudo T, Chandra FA, Ahn SS. The effectiveness of percutaneous transluminal angioplasty for the treatment of critical limb ischemia: A 10-year experience. J Vasc Surg. 2005; 41:423-435. Discussion 435. [PubMed: 15838475]. 